\title{
Roundabout users subjective safety - case study from Upper Silesian and Masovian Voivodeships (Poland)
}

\section{Elżbieta Macioszek, Agata Kurek}

Transport Systems and Traffic Engineering Department, Faculty of Transport and Aviation Engineering, Silesian University of Technology, Krasińskiego 8 Street, 40-019 Katowice, Poland

\begin{abstract}
The main objective of the work was inventory intersections like roundabouts in all cities with poviat rights located in two voivodeships of Poland: Upper Silesian and Masovian, and then performing users surveys of registered roundabouts. Survey research had two main objectives. The first one was to learn how vehicle drivers, pedestrians and cyclists perceived roundabouts as safe or unsafe road solutions. The second one was to learn about the behaviour of three users groups: vehicle drivers, pedestrians and cyclists on this type of road infrastructure in terms of traffic safety.
\end{abstract}

KEYWORDS: Roundabouts; road users behaviours; questionnaires; subjective safety; preference studies; road traffic safety; road traffic engineering; road transport.

\section{INTRODUCTION}

One of the conditions for the proper functioning of each type of intersections is the behaviour of road users, i.e. drivers, pedestrians and cyclists by the road traffic laws. However, the behaviours of transport network users are often different than those required by road traffic laws (Szczuraszek, T., et al., 2010). Especially in the situation of ever-increasing traffic volumes (Macioszek, E., 2019c). The behaviour of road users is subject to multifaceted scientific research. The aim is to learn about factors that influence decisions made by road users. For this purpose are used dynamic research methods (Cacciabue, 2007), (Wahlberg, 2009), (Sharma et al., 2019), (Sullman et al. 2002), (Guzek et al., 2009), (Macioszek, E., 2011). Transport network users sometimes make wrong decisions or make mistakes in road traffic.
This can lead to the occurrence of traffic incidents of different severity.

Road traffic incidents statistics indicate that among all types of intersections, the least number of injured and fatalities is registered on roundabouts. This fact contributed to the popularity of this type of intersections. In Poland, for almost 30 years, they have been willingly and often used solution for crossing roads and streets. The main advantages of roundabouts include (Macioszek, E., 2010), (Macioszek, 2019a), (Macioszek, 2019b):

- a small number of collision points compared to other types of intersections,

- low speed of crossing the intersection,

- greater pedestrian protection, caused by traffic streams separation at the entry from the traffic stream at the exit.

This means that pedestrians have the opportunity of separately crossing roundabout entry and exit,

- less delay compared to other types of intersections and hence lower environmental pollution, lower fuel consumption and lower travel costs, increase in traffic flow compared to other types of intersections.

At roundabout can be observed different users groups i.a. drivers, cyclists, pedestrians. According to scientific literature, i.a. (Guido, G., Vitale, A., 2006), (Mackie, H.W., et al., 2013), (Moller, M., Hels, T., 2008), (Szczuraszek, T., et al., 2013), (Małecki., K. et al., 2017), (Małecki, K., 2017), (Małecki, K., 2018), (Macioszek, E., 2019d). Many features influence on their behaviour, i.a. traffic volume, the share of heavy vehicles, the share of two-wheelers vehicles and the share of pedestrians in road traffic, the number of lanes, presence or ab- 
sence of support infrastructure, traffic organization and many others.

The paper presents the results of roundabouts inventory in the research area, which were cities with poviat rights in two voivodeships: Upper Silesian and Masovian. Then an attempt made to identify, present and describe the behaviour of road users at roundabouts. For this purpose, surveys were carried out at single-lane and multi-lane roundabouts in the research area. The questions in the survey aimed to provide information about i.a.: drivers attention to horizontal and vertical marking, which inform about the proper moving at the roundabout, choosing the correct traffic lane, respect for yield right of way to pedestrians using pedestrian crossing located at roundabouts entries and exits. These questions were also to answer how vehicle drivers, pedestrians and cyclists perceived roundabouts as safe or unsafe road solutions.

\section{CHARACTERISTIC OF THE RESEARCH AREA}

The Upper Silesian Voivodeship is characterized by the highest urbanization rate in the country. The existing road infrastructure is well developed in com- parison to other voivodeships. There are dense road and street network. The road system of this area, in particular the Katowice agglomeration, is characterized by one of the largest traffic flow in passenger and freight transport in the country. According to statistical data from Municipal Police Headquarters (Police Headquarters, 2016), the Upper Silesian Voivodeship is characterized by the second largest accident density ratio per 100 kilometres of public roads in Poland. Last year there were 3650 accidents in which 257 people were killed and 4347 people were injured. About $30 \%$ of this type of road incidents occurred at road intersections. The inventory of roundabouts was carried out in the Upper Silesian Voivodeship. This type of intersections was identified in all 19 cities with poviat rights. The area covered by the analysis is over $1800 \mathrm{~km}^{2}$ which is $14.6 \%$ of the total area of the Upper Silesian Voivodeship.

According to Statistical Yearbook of Masovian Voivodeship (Statistical Yearbook of Masovian Voivodeship, 2017), the Masovian Voivodeship has a population of 5365898 inhabitants, which is $14.1 \%$ of the Polish population. The Masovian Voivodeship has an area of $35558 \mathrm{~km}^{2}$ consists of 81 cities and 5 cities with poviat rights. In the case of

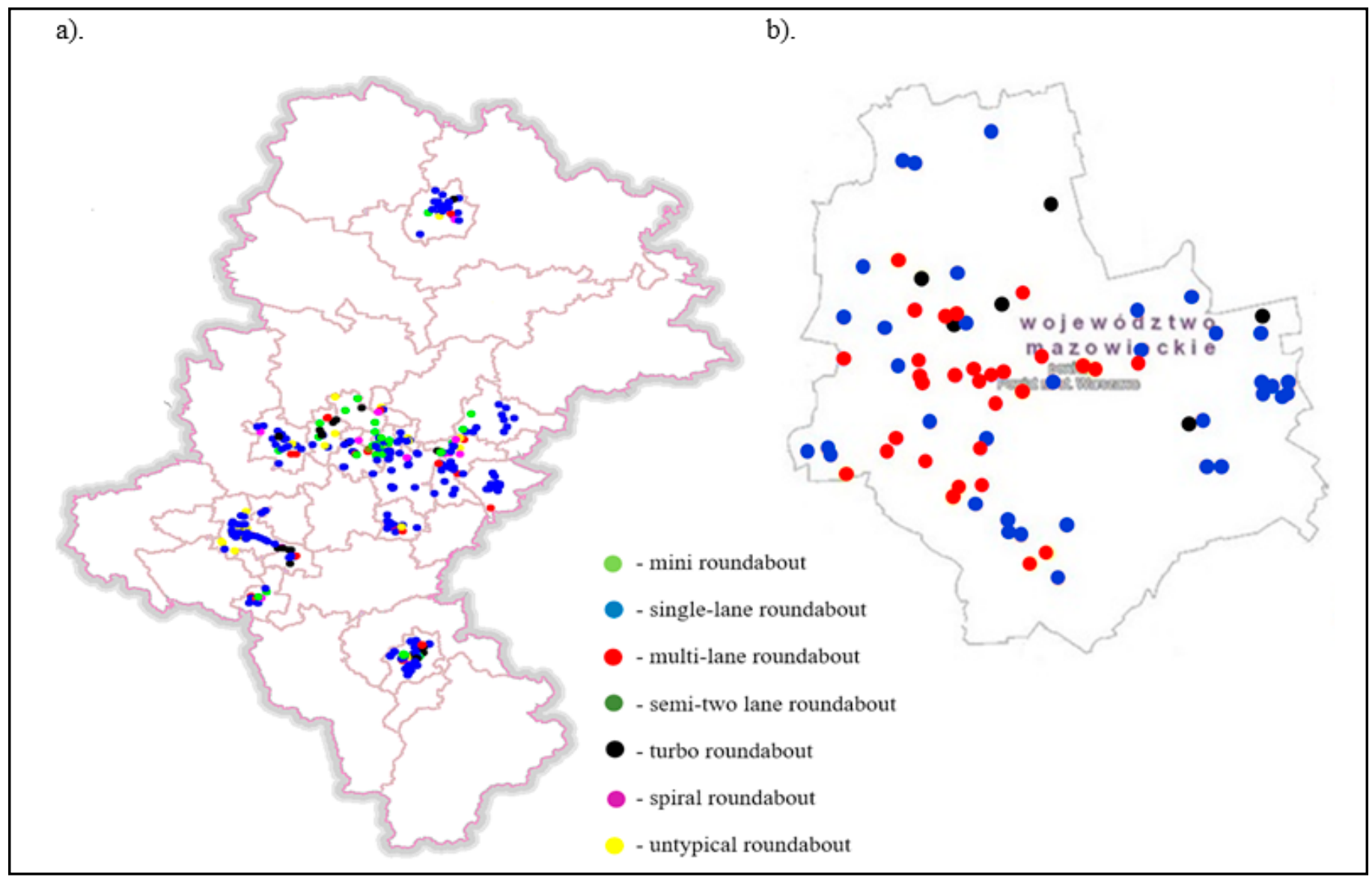

Fig. 1. Localization of roundabouts in cities with poviat rights in a). Upper Silesian Voivodeship, b). Masovian Voivodeship 
this voivodeship, research was conducted for five cities with poviat rights. There are Warszawa, Radom, Płock, Ostrołęka and Siedlce.

Collected data about roundabouts in cities with poviat rights in both voivodeships included information about:

- localization of the roundabout (built-up area, outside the built-up area, outskirts of built-up area),

- name of crossing streets, roundabout name,

- roundabout type (mini roundabout, single-lane roundabout, multi-lane roundabout (distinguishing the number of lanes on the circular roadway at the roundabout and on entries), turbo roundabout, spiral roundabout; semi-two lane roundabout, others - untypical roundabout),

- the external diameter of the roundabout (in the case of turbo roundabouts - first radius of the circular roadway of the roundabout R1),

- development of the central island (low, medium, high development),
- form of central island development (greenery, elements of small architecture, others),

- additional notes.

Data were obtained mainly from public institutions in cities, from as a result of inventory and from all other available sources. Fig. 1 presents the results of the work.

In the Upper Silesian Voivodeship were inventoried 404 roundabouts in all cities with poviat rights, including 29 mini roundabouts, 289 single-line roundabouts, 32 multi-lane roundabouts, 6 semi-two lanes roundabouts, 25 turbo roundabouts and 23 roundabouts with the untypical shape of the central island.

In turn, in the area of five cities with poviat rights in the Masovian Voivodeship were inventoried 109 roundabouts, including 48 single-lane roundabouts, 40 multi-lane roundabouts, 10 semi-two lane roundabouts, 10 turbo roundabouts and 1 roundabout with the untypical shape of the central island. Most of them are in Warsaw (80), while the least in Plock (4). Fig. 2 shows the distribution of roundabouts in cities with poviat rights in both voivodeships.

a).

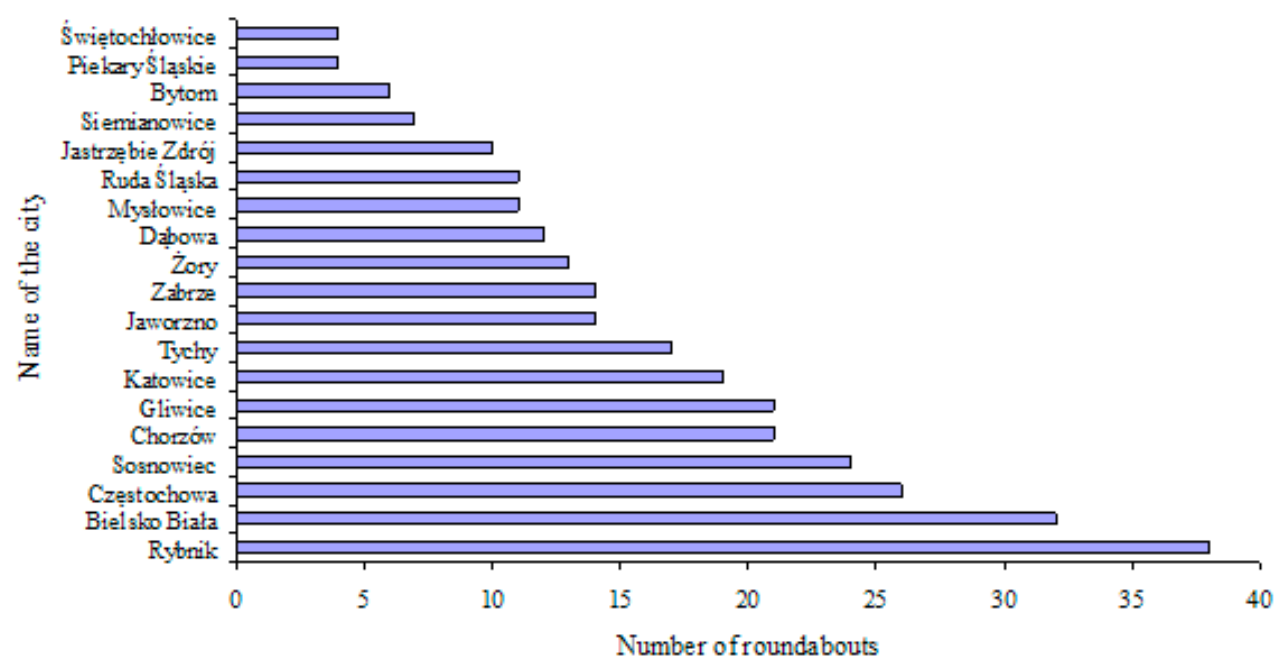

b).

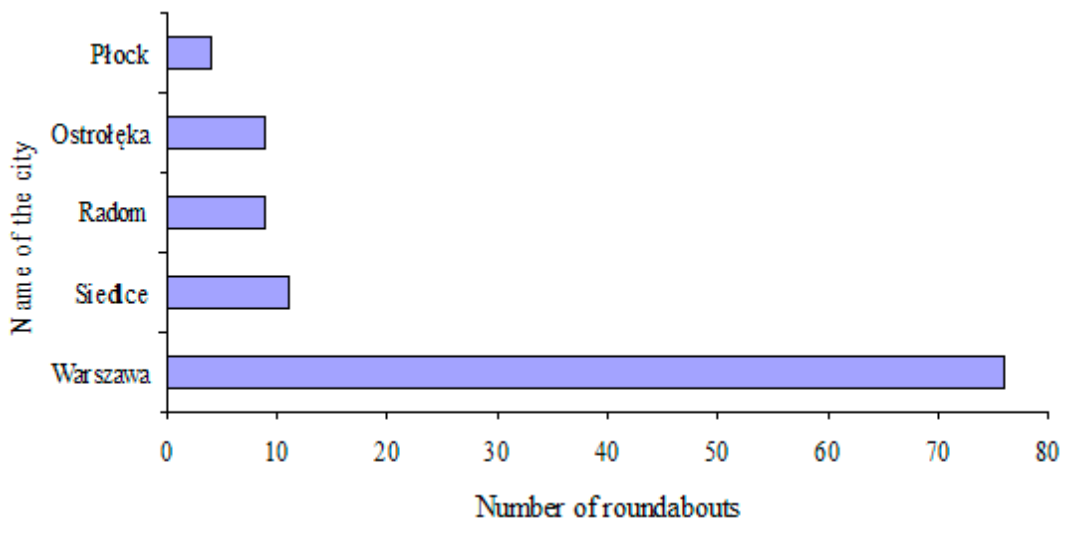




\section{DESCRIPTION OF THE SURVEY RESEARCH}

Survey research had two main objectives. The first one was to learn how vehicle drivers, pedestrians and cyclists perceived roundabouts as safe or unsafe road solutions. The second one was to learn about the behaviour of three users groups: vehicle drivers, pedestrians and cyclists on this type of road infrastructure in terms of traffic safety. The paper attempts to check and verify the hypothesis that roundabout users - in particular single-lane roundabouts - generally perceived positively the roundabouts. Preference researches were carried out among roundabout users to verify this hypothesis. The questions in the survey aimed to provide information about, i.a.: users perception of roundabouts, drivers attention to horizontal and vertical marking, which inform about proper traffic at the roundabout, choosing the right lane, respecting the yield right of way for pedestrians using pedestrian crossings located at roundabouts entries and exits, etc. The survey collected 1800 answers: 1634 interviews were conducted in the field, while 166 were conducted via the Internet. Due to the method of selecting the respondents, the surveys were quasi-representative studies. It is caused due to the surveyed group of respondents complied the requirements of the representative method only in some aspects. The research was carried out from September 2017 to September 2019. The ranked was used in the questions in which the respondents were asked to sort the answers in ascending order or to indicate the best solution in their opinion. In all questions, the best solution - according to respondents received a rank of 1.00 , while the worst -3.00 or 6.00 (depending on the number of possible answers). On this basis, the average rank value was calculated for each answer. The survey consisted of single and multiple choice closed questions and ranking questions. The questionnaire was addressed to respondents with a driving license and moving at roundabouts.

This type of research - i.e. questionnaire has been very often used in transport engineering analysis. The content, as well as the form of the questionnaire, were designed based on a wide review of the scientific literature. Questionnaire internal consistency and his reliability were modelled using the Cronbach's alpha coefficient $(\alpha)$ (Carmines, E., 1982), (Cronbach, L., 1951), (Yurdugul, H., 2008), (Cortina, J., 1993), (Streiner, D., 2003), (Tavakol, M., et al. 2011). The factor value was equal $\alpha=0.658$, which confirmed that the constructed questionnaire was a tool that could be used to measure how vehicle drivers, pedestrians and cyclists perceived roundabouts as safe or unsafe road solutions and judge how is the behaviour of three users groups: vehicle drivers, pedestrians and cyclists on this type of road infrastructure in terms of traffic safety. The final form of the questionnaire was discussed, assessed, and corrected by an expert team (three independent experts assessed its layout, readability, style, and transparency of questions). All respondents had early agreed to participate in the survey. The survey was conducted on weekdays and weekends to obtain a large size and varied answers. The random sampling technique was used to select roundabouts users. Only respondents over 18 years took part in the survey. The questionnaires were examined in terms of data correctness and completeness (e.g., the questionnaires were rejected in which: respondents indicated that they were using the roundabouts for the first time; respondents said that they contained incomplete information; respondents could not indicate their assessment, e.g., "I do not know", "I have no opinion of my own", "I have not such as situation").

The survey was divided into 5 parts. The first part was an illustrated theoretical introduction, which aimed to familiarize the respondents with the basic terms dedicated to roundabouts. The survey included all roundabout types: single-lane, double-lane, semitwo lane, spiral and turbo roundabouts. In order to make it easier for respondents to understand different types of roundabouts, the survey introduces definitions and diagrams of each type of roundabout. Moreover, not all of the above-mentioned roundabout types are often found on the transport network of the research area. Single-lane and double-lane roundabouts are the most common types (Fig. 1).

In the second part of the questionnaire was collected information necessary to construct the personal profile of the examined group of people. Respondents were asked about gender, age, number of years having a driving license, place of residence, professional activity, frequency of moving at the roundabout, the most often used type of roundabouts by them etc.

In the following parts of the survey, respondents provided answers about the perception of roundabouts as safe/unsafe road solutions and evaluation of the road users behaviours. The third part of the survey was about the characteristics of driver behaviour. In this part, the respondents were asked questions, which checking whether the respondents pay atten- 
tion to vertical and horizontal marking and how they behave to pedestrians - whether they yield right of way to pedestrians as drivers. They were also asked for their opinion whether other drivers yield right of way to them when they are pedestrians waiting at the pedestrian crossing.

The fourth part of the survey was optional and was addressed to those drivers who also move by bike on the roundabout. Respondents were asked about how they move on the circular roadway of a roundabout and whether they obey the traffic laws when they choosing a lane. The same questions were also formulated for people who also move at roundabouts as motorcyclists.

The last part of the survey concerned the respondent's opinions on the impact of different features and equipment on their behaviour. The respondents assessed that i.a. the development of the central island has an impact on their behaviour and what type of the development of central island causes speed reduction at the roundabout. The respondents were also asked whether they were drivers they moved at the roundabout with infrastructure elements that physically separate the movement of cyclists from car traffic.

\section{ANALYSIS OF SURVEY RESULTS}

The collected data can be analyzed taking into account various respondent classifications (e.g. age, gender, etc.). The paper presents an analysis of selected features. Fig. 3a presents the age structure of responders. Most of all respondents were people from the age group $<45-50$ ) and it is $27.83 \%$ of all respondents. At the second place are people from the age group $<40-45$ ). Their participation in the study was $21.67 \%$. The least of all respondents were people from the age group (17-20) and aged over 60 years. Their participation in the study was less than $1.00 \%$. $32 \%$ of women and $68 \%$ of men participated in the survey. Fig. $3 \mathrm{~b}$ shows the distribution of the number of years having a driving license. The least of the group were respondents with a driving license of up to 5 years and over 50 years. The most of group were respondents with driving licenses for 20-25 years (25.50\%). This result is probably caused by the fact that most of the respondents were people from the age group 45-50.

In turn, Fig. 4a presents the structure of respondents residence. The diagram shows that $54 \%$ of respondents live in a large city with a population of over
350000 . Hence, it can be assumed that these drivers move at roundabouts dynamically, with a high frequency, in conditions of high traffic. In the analysis was also included the structure of respondents professional activity. The most of group in the study were people working (up to $72 \%$ of the surveyed group). The next largest groups were retirees and pensioners (15\%). Students (11\%) and school students (2\%) also participated in the study.

a).

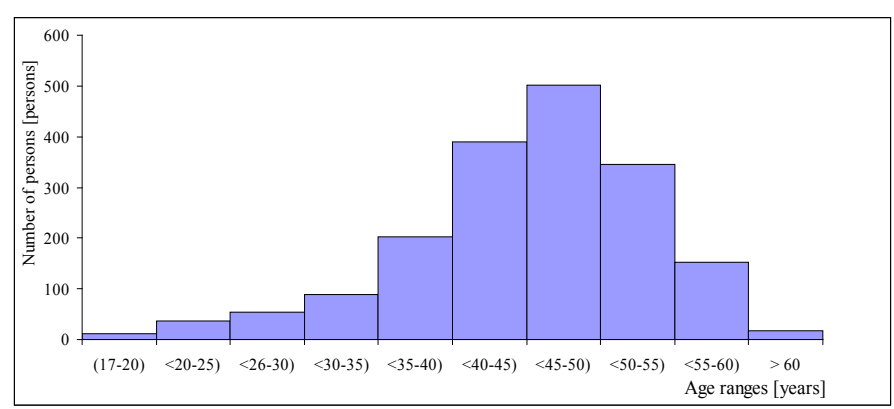

b).

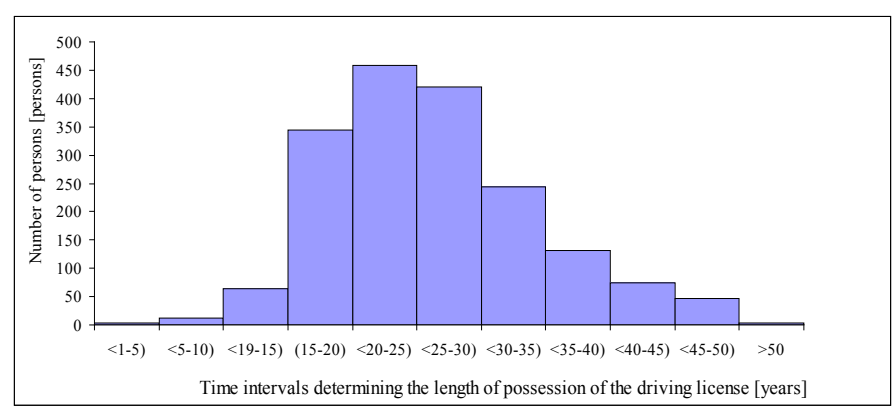

Fig. 3. (a). The age structure of responders; (b). The number of years having a driving license

Fig. $4 \mathrm{~b}$ presents the analysis results of the frequency of moving at the roundabout. The frequency of travelling at the roundabout is due to i.a. the size of the city, professional activity. $37 \%$ of respondents move at roundabouts a few times a week and $46 \%$ every day. It can be because most of the respondents live in large cities, moreover, they are professionally active.

Respondents also answered the questions in which they were as drivers, cyclists and pedestrians. This was aimed at checking the impact of changing the means of transport on the perception of road solutions. According to respondents, the single-lane roundabout is considered the safest solution by drivers and cyclists, in the case of three inlets and four inlets intersections (i.e. respondents perceived them as the safest). Then are respectively the intersection with traffic lights and the intersection without traffic lights, according to respondents opinion (Fig. 5a and Fig. 5b). 
a).

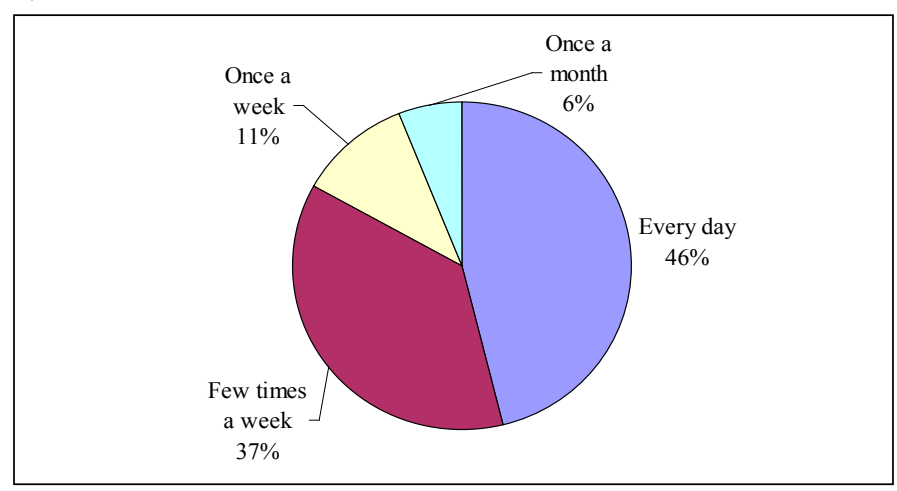

b).

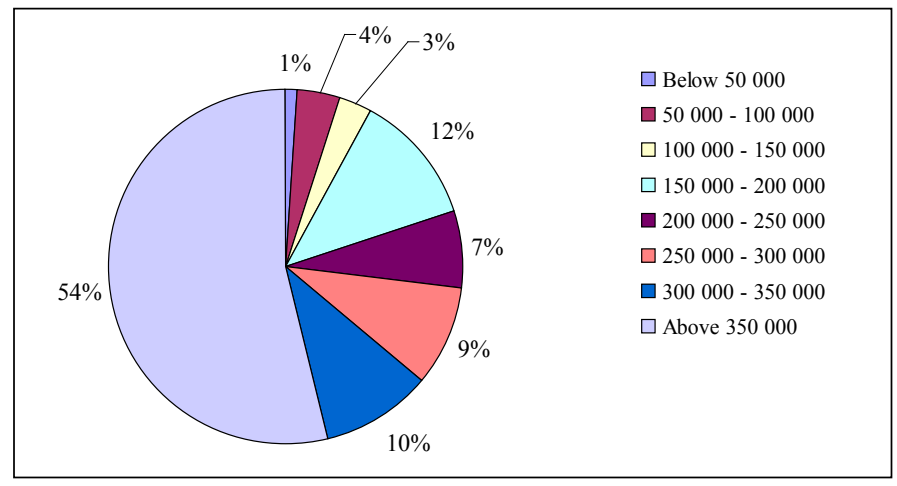

Fig. 4. (a). The residence structure of responders; (b). The frequency of travelling at roundabouts

a).

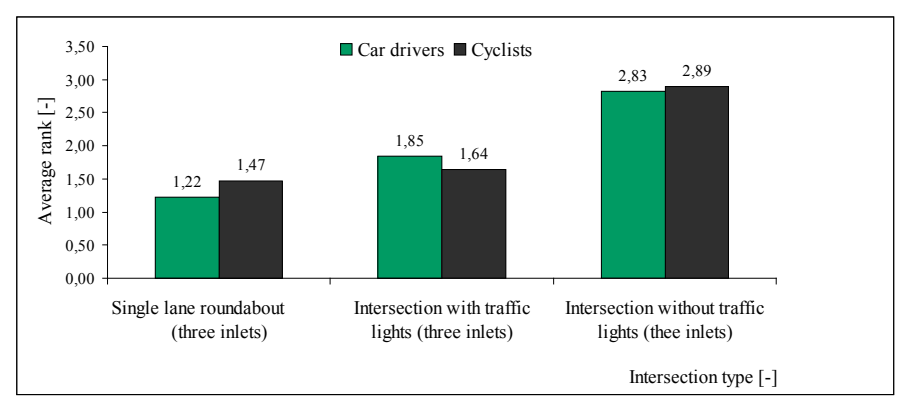

b).

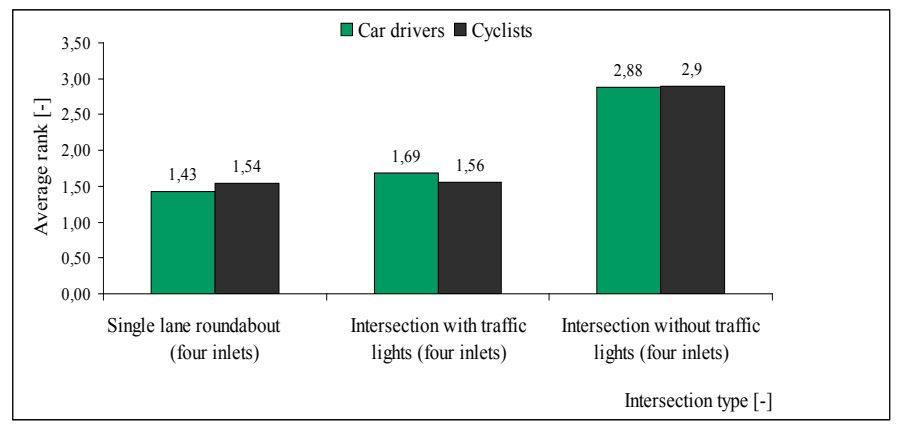

Fig. 5. Drivers and cyclists perception of different type of intersections a). three inlets, b). four inlets, in the aspect of road traffic safety

Fig 6 shows the perception of various types of roundabouts by vehicle drivers and cyclists as safe road solutions. Fig. 6 indicates that the safest roundabout type is single-lane roundabouts, according to respondents.

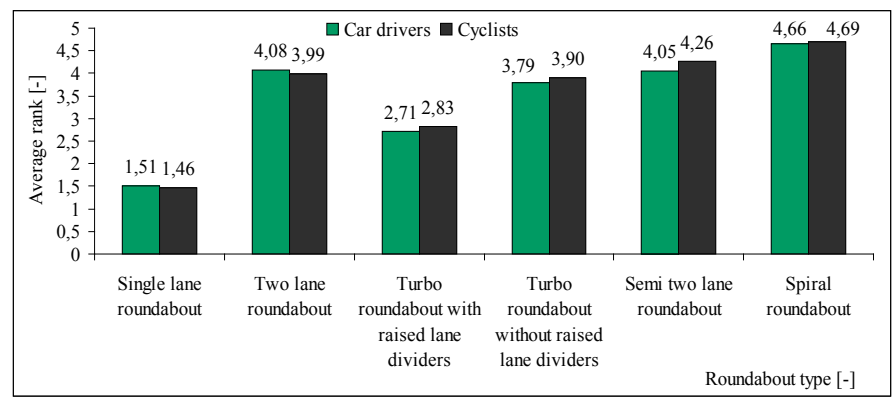

Fig. 6. Drivers and cyclists perception of different types of roundabouts as safe road solutions

According to respondents, in the second place are turbo roundabouts with raised lane dividers. In the third place are turbo roundabouts with lane separators in the form of a continuous line of P-2 type. Then are the semi-two lane roundabouts. In the penultimate place are two lane roundabouts, which are commonly founded on the Polish road network. The worst are spiral roundabouts in respondents opinion. In turn, the biggest difference in the perception of roundabouts by vehicle drivers and the cyclist was noted in the case of semi-two lane roundabouts $(0.21)$. The cyclists in contrast to the vehicle drivers, consider that the semi-two lane roundabouts are less safety road solutions. Differences in the perception of roundabouts by vehicle drivers and cyclists are small for the other types of roundabouts.

Respondents in the role of pedestrians, in their responses, noticed the need to use pedestrians refuge islands at inlets. Their occurrence makes much easier to cross the road and thus increases the level of road traffic safety.

The survey also allowed the identification of those respondents who participated in traffic incidents at the roundabout. Those respondents were asked to indicate participants of the traffic incidents in which they participated (i.e. vehicle-vehicle, pedestrian-vehicle, cyclist-vehicle, vehicle - an element of infrastructure), type of traffic incident and its causes. The respondents participated in such types of traffic incidents on roundabouts as: side-impact, rear impact and collision with an element of infrastructure. According to respondents opinion, the most often causes of these traffic incidents were: 
- failure to yield the right of way,

- failure to adapt the speed to road traffic conditions,

- not respecting road signs and other signals,

- failure to maintain a safe distance between vehicles,

- poor road conditions.

The types of traffic incidents indicated by the respondents and their causes are characteristic for roundabouts. What is confirmed in the scientific literature e.g. (Daniels, S., et al., 2009), (Daniels, S., et al., 2010a), (Daniels, S., et al., 2010b), (Isebrands, H., 2009), (Saccomanno, F.F., et al., 2008), (Mandavilli, S., et al., 2009). (Retting, R.A., et al., 2001).

\section{SELECTED RESULTS OF STATISTICAL INFERENCE - CROSS-ANALYSIS}

Based on the results of descriptive statistics presented in the previous chapter some statistical inference like cross-analysis were performed. The cross-analysis allow observing the relationship between two questions asked in the survey. The results are presented in the form of a table in which columns and rows form two selected questions along with possible answers. Each table cell indicates the number of respondents who provide a specific combination of answers. These analyzes were prepared using IBM SPSS Statistics Software. Cross-analysis are used to present data, where the main measure is the number of responses and the percentage of the group. In subsequent cross-analysis, it was checked whether in the surveyed group of respondents from the Masovian Voivodeship differed from the respondents from the Upper Silesian Voivodeship in terms of:

- the age structure of responders,

- the structure of the frequency crossing the roundabouts,

- the structure of the sources of information about roundabouts,

- the structure of the number of years having a driving license by the responders,

- perception by car drivers of various types of three/four inlets intersections in the aspect of road traffic safety,

- perception by cyclists of various types of three/four inlets intersections in the aspect of road traffic safety,
- the perception of various types of roundabouts by drivers of vehicles as safe road solutions,

- the perception of various types of roundabouts by cyclists as safe road solutions.

In each case, the analyzed variables are nominal variables. Due to the fact that nominal statistics can not be used to calculate other statistics such as the mean, standard deviation, the best solution to present the results is to present the number (number of people or percentage share) for given answers. This form of data presentation provides full insight into the obtained results. The tables below show the percentage of response categories for one and the other variable and how the results of vehicle drivers for these categories were distributed. Due to the limitations related to the paper volume in the following cross-analyses selected results of the conducted research were presented.

Table 1 presents the structure of the sources of information about proper behaviours at the roundabouts for roundabouts users living in the Masovian and the Upper Silesian Voivodeships. The survey was structured in such a way that users had to indicate only one source of information that was basic for them (it was assumed that the respondents receive information from several sources, but one of them is leading). Based on the data presented in Table 1 can be concluded that the basic source of knowledge about proper behaviours at the roundabouts both for users living in the Masovian as well as in the Upper Silesian Voivodeships are respectively in the following driving courses, the information in the website (in the case of roundabouts users living in the Masovian Voivodeship) and information acquired during the classes at school/university (in the case of roundabouts users living in the Upper Silesian Voivodeship). During the analysis of partial results, can be stated i.a. that roundabouts users living in the Upper Silesian Voivodeship's basic knowledge about roundabouts were much more likely than roundabouts users living in the Masovian Voivodeship to gain from classes at school/universities.

Based on the data presented in Table 2 can be concluded that from among various types of three inlets intersections, according to respondents perception, the safest road solutions are perceived three inlets single-lane roundabouts and successively three inlets intersections with traffic lights. Analyzing the partial results, i.a. can be stated that 
car drivers living in the Upper Silesian Voivodeship more often than car drivers living in the Masovian Voivodeship perceive three inlets intersections without traffic lights as safe road solutions. This conclusion has some confirmation in reality. The analyzed cities with poviat rights located in the Upper Silesian Voivodeship have a smaller number of inhabitants than the analyzed cities with poviat rights in the Masovian Voivodeship. Hence, with lower traffic, one should expect a higher level of road traffic safety that occur at intersections.

A similar situation as in the case of perception by car drivers various types of three inlets intersections takes place in the case of perception four inlets intersections (Table 3). According to respondent perception, among different solutions, the safest road solutions are perceived four inlets single-lane roundabouts and next four inlets intersections with traffic lights.

Table 1. The structure of the sources of information about proper behaviours at the roundabouts for roundabouts users living in the Masovian and the Upper Silesian Voivodeships.

\begin{tabular}{lccc}
\hline $\begin{array}{l}\text { Sources of information about } \\
\text { roundabouts }\end{array}$ & $\begin{array}{c}\text { Users living in the Masovian } \\
\text { Voivodeship } \\
{[\%]}\end{array}$ & $\begin{array}{c}\text { Users living in the Upper Silesian } \\
\text { Voivodeship } \\
{[\%]}\end{array}$ & $\begin{array}{c}\text { Total } \\
{[\%]}\end{array}$ \\
\hline Driving course & 68.15 & 75.80 & 75.35 \\
Paper on the website & 16.88 & 9.12 & 12.21 \\
Classes at school/university & 6.35 & 11.28 & 7.02 \\
TV program & 4.05 & 2.16 & 2.31 \\
Paper in the newspaper & 2.17 & 1.34 & 1.75 \\
Fact sheet & 2.26 & 0.30 & 1.26 \\
Other & 0.14 & 0.00 & 0.10 \\
Sum & 100.00 & 100.00 & 100.00 \\
\hline
\end{tabular}

Table 2. The perception by car drivers of various types of three inlets intersections in the aspect of road traffic safety for users in the Masovian and the Upper Silesian Voivodeships.

\begin{tabular}{lccc}
\hline $\begin{array}{l}\text { Perception by car drivers of } \\
\text { various types of three inlets } \\
\text { intersections as safe road solutions }\end{array}$ & $\begin{array}{c}\text { Car drivers living in the Masovian } \\
\text { Voivodeship } \\
{[\%]}\end{array}$ & $\begin{array}{c}\text { Car drivers living in the Upper } \\
\text { Silesian Voivodeship } \\
\text { [\%] }\end{array}$ & $\begin{array}{c}\text { Total } \\
\text { [\%] }\end{array}$ \\
\hline Single-lane roundabouts & 59.40 & 59.36 & 64.28 \\
Intersections with traffic lights & 30.67 & 29.42 & 27.30 \\
Intersections without traffic lights & 9.93 & 11.22 & 8.42 \\
Sum & 100.00 & 100.00 & 100.00 \\
\hline
\end{tabular}

Table 3. The perception by car drivers of various types of four inlets intersections in the aspect of road traffic safety for users in the Masovian and the Upper Silesian Voivodeships.

\begin{tabular}{lccc}
\hline $\begin{array}{l}\text { Perception by car drivers of } \\
\text { various types of four inlets } \\
\text { intersections as safe road solutions }\end{array}$ & $\begin{array}{c}\text { Car drivers living in the Masovian } \\
\text { Voivodeship } \\
{[\%]}\end{array}$ & $\begin{array}{c}\text { Car drivers living in the Upper } \\
\text { Silesian Voivodeship } \\
\text { [\%] }\end{array}$ & $\begin{array}{c}\text { Total } \\
\text { [\%] }\end{array}$ \\
\hline Single-lane roundabouts & 61.72 & 58.96 & 60.62 \\
Intersections with traffic lights & 32.38 & 31.64 & 29.48 \\
Intersections without traffic lights & 5.90 & 9.40 & 9.90 \\
Sum & 100.00 & 100.00 & 100.00 \\
\hline
\end{tabular}


Table 4. The perception of various types of roundabouts by vehicle drivers from the Masovian and the Upper Silesian Voivodeships as safe road solutions.

\begin{tabular}{lccc}
\hline $\begin{array}{l}\text { Perception of various types of roundabouts } \\
\text { by vehicle drivers as safe road solutions }\end{array}$ & $\begin{array}{c}\text { Users living in the } \\
\text { Masovian Voivodeship } \\
{[\%]}\end{array}$ & $\begin{array}{c}\text { Users living in the Upper } \\
\text { Silesian Voivodeship } \\
{[\%]}\end{array}$ & $\begin{array}{c}\text { Total } \\
\text { [\%] }\end{array}$ \\
\hline Single-lane roundabouts & 41.14 & 45.71 & 44.60 \\
Two lane roundabouts & 13.93 & 12.63 & 13.01 \\
Semi-two lane roundabouts & 11.69 & 10.49 & 10.53 \\
Spiral roundabouts & 4.82 & 3.36 & 3.12 \\
Turbo roundabouts with raised lane dividers & 17.8 & 21.59 & 20.29 \\
Turbo roundabouts without raised lane dividers & 10.62 & 6.22 & 8.45 \\
Sum & 100.00 & 100.00 & 100.00 \\
\hline
\end{tabular}

In turn, among all types of roundabouts, also single-lane roundabouts are considered as the safest solutions (both by users from the Masovian as well as from the Upper Silesian Voivodeships). Next turbo roundabouts with raised lane dividers. Detailed analysis shows that users from the Upper Silesian Voivodeship more often than users from the Masovian Voivodeship perceive turbo roundabouts with raised lane dividers as safe road solutions. Table 4 presents the results of cross-analysis.

\section{DISCUSSION AND CONCLUSIONS}

Roundabouts are becoming more and more popular every year, which is why they are willingly and often designed on the transport network of Polish cities (Sładkowski, A., et al., 2018). Designing them on the transport network requires prior detailed analysis to ensure efficient service for their users on both private journeys and those supporting city logistics (Cieśla, M., 2015), (Cieśla, M., et al., 2017), (Szczucka-Lasota, B., 2017). Hence, it is worth learning the opinion of users about the perception of different types of roundabouts. The main objective of the work was inventory roundabouts in cities with poviat rights located in two voivodeships of Poland: Upper Silesian and Masovian, and then performing users surveys of registered roundabouts. Survey research had two main objectives. The first one was to learn how vehicle drivers, pedestrians and cyclists perceived roundabouts as safe or unsafe road solutions. The second one was to learn about the behaviour of three users groups: vehicle drivers, pedestrians and cyclists on this type of road infrastructure in terms of road traffic safety. The analyzes presented in the paper confirmed the hypothesis that roundabouts users in Poland - in particular single-lane roundabouts - generally perceive positively roundabouts. The analyzes allowed to formulate the following conclusions:

- the single-lane roundabouts are the most common roundabouts types on the Polish transport network. They are designed and built both in built-up areas as well as outside of them. The single-lane roundabouts are often in housing development, surrounded by shopping centres and directly at the entries and exits of expressways. The single-lane roundabouts are also used near national road intersections. That is why most respondents cross them on their way to work, school, or university, regardless of the size of their place of residence. In turn, multi-lane roundabouts are characterized by large cities, on streets with heavy traffic volume,

- the vehicle drivers and the cyclists considered that the safest type of roundabout is singlelane roundabouts. According to respondents, in the second place are turbo roundabouts with raised lane dividers. In the third place are turbo roundabouts with lane separators in the form of horizontal markings as a continuous line of P-2 type. Then are the semi-two lane roundabouts. In the penultimate place are two lane roundabouts, which are most often founded on the Polish road network. The worst are spiral roundabouts in respondents opinion, 
- the respondents in the role of pedestrians in their responses noticed the need to use pedestrians refuge islands at inlets. Their occurrence makes it much easier to cross the road and thus increases the level of road traffic safety,

- the results of surveys also confirmed that drivers pay attention to the road traffic organization. This has a function to inform and assists the vehicle driver in making decisions about the further direction of travel. At the inlets of multi-lane roundabouts, drivers choose the right lanes based on the information presented on vertical marking located on masts or booms above the lanes at the inlets (especially turbo roundabouts) and based on good quality horizontal markings. That was confirmed by the obtained results. The vertical and horizontal marking used on turbo roundabouts is legible for drivers. It was confirmed by respondents answer,

- research also confirmed that $87 \%$ of respondents while driving focus on vertical marking (vertical markings installed on pillars, masts, booms, gates) and horizontal marking painted on the surface of lanes which inform about the correct choice of the traffic lane. In turn, $13 \%$ of respondents admitted that they do not focus on vertical and horizontal markings. As a justification of their behaviour, respondents indicated, i.a. following arguments: insufficient visibility of vertical signs, focusing on vehicles moving on the main road, ignoring information given on road markings, routine,

- the survey also checked whether drivers yield right of way to pedestrians at pedestrian crossings located at the roundabouts entries and exits. In both cases, more than half of the surveyed drivers yield right of way to pedestrians. When they coming to a roundabout, it is less than $72 \%$, while they leaving the circular roadway of a roundabout - 61\%. Comparing the respondents answers from both road situations, it can be stated that drivers coming to the roundabout focus more attention on pedestrians and more often stop before pedestrian crossing to yield right of way to pedestrians. This fact may be due to the need to reduce the speed at the inlet of the roundabout to yield right of way to drivers of vehicles on the circular roadway. The drivers focus less on pedestrians waiting for an opportunity to cross the road while leaving the roundabout circular roadway,

- the survey also checked whether in the assessment of pedestrians the drivers yield right of way when they crossing pedestrian crossings located at roundabouts. In the opinion of the majority of respondents, i.e. $68 \%$, drivers yield right of way to pedestrians in front of or already at a pedestrian crossing. This result may indicate the correct cooperation of drivers and pedestrians in road traffic only for some group of road users. However, the behaviour of drivers who do not respect the priority of pedestrians at pedestrian crossings is disturbing (32\%),

- the obtained data shows that $46 \%$ of vehicle drivers also use roundabouts as a cyclist,

- the majority of respondents considered that the development of the central island has some impact on the behaviour of drivers (73\%) as well as the speed of moving at the roundabout (72\%). Respondents indicated that the development of the central island causes, i.a.: a speed reduction due to the limited visibility of the opposite roundabout inlet, an increase in the driver's attention as well as the possibility of dispersing it. Respondents indicated that the most effective to reduce speed on the roundabout is to develop central islands in high greenery and elements of small architecture.

Acknowledgements: The authors would like to thank the Students, Graduate of engineering and master degree from Department of Transport Systems and Traffic Engineering at Faculty of Transport and Aviation Engineering at Silesian University of Technology, who carried out many difficult and labor-intensive field studies in 2017-2019.

\section{REFERENCES}

Cacciabue, C.P. (2007). Modelling Deiver Behaviour in Automotive Environments. Critical Issues in Driver Interactions with Intelligent Transport Systems. London, Springer-Verlag.

Carmines, E.G., Zeller, R.A. (1982). Reliability and Validity Assessment, 5th ed. Sage Publications Inc.: Beverly Hills, CA, USA, 1982. 
Cieśla, M. (2015). Outsourcing strategy selection for transportation services based on the make-or-buy decision. Transport Problems 10, issue 2, p. 91-98.

Cieśla, M., Mrówczyńska, B. (2017). Problem of Medicines Distribution on the Example of Pharmaceutical Wholesale. In: Zawislak, S., Rysiński, J. (eds.) Graph-Based Modelling in Engineering. Mechanisms and Machine Science 42. Springer, Cham, p. 51-65.

Cortina, J.M. (1993). What is Coefficient Alpha? An Examination of Theory and Applications. J. Appl. Psychol. 104, p. 78-98.

Cronbach, L.J. (1951). Coefficient alpha and the internal structure of tests. Psychometrica 16, p. 297-334.

Daniels, S., Brijs, T., Nuyts, E., Wets, G. (2009). Injury crashes with bicyclists at roundabouts: influence of some location characteristics and the design of cycle facilities. Journal of Safety Research, 40, issue 2, 141-148.

Daniels, S., Brijs, T., Nuyts, E., Wets, G. (2010a). Explaining variation in safety performance of roundabouts. Accident Analysis \& Prevention, 42, issue 2, 393-402.

Daniels, S., Brijs, T., Nuyts, E., Wets, G. (2010b). Externality of risk and crash severity at roundabouts. Accident Analysis \& Prevention, 42, issue 6, 1966-1973.

Guido, G., Vitale, A. (2006). Analysis of user behaviour at a roundabout under car-following conditions. WIT Transactions on The Built Envinronment, 89, 317-326.

Guzek, M., Lozia, Z., Zdanowicz, P., Jurecki, R.S., Stańczyk, T.L. (2009). Research on behaviour of drivers in accident situation conducted in driving simulator. Journal of KONES vol. 16, No. 1, pp. 173-183.

Isebrands, H. (2009). Crash analysis of roundabouts at highspeed rural intersections. Transportation Research Record: Journal of the Transportation Research Board, vol. 2096, issue 1, 1-7.

Macioszek, E. (2010). The application of HCM 2010 in the determination of capacity of traffic lanes at turbo roundabout entries. Transport Problems, Vol. 11, issue 3, 2016, p. 77-89.

Macioszek, E. (2011). The Influence of Motorcycling and Cycling on Small One-Lane Roundabouts Capacity. In: J. Mikulski (ed.) Transport Systems Telematics. Communications in Computer and Information Science 239. Springer-Verlag, Berlin Heidelberg 2011, p. 291-298.

Macioszek, E. (2019a). The Passenger Car Equivalent Factors for Heavy Vehicles on Turbo Roundabouts. Frontiers in Built Environment. Section Transportation and Transit Systems vol. 5, 1-13.

Macioszek, E. (2019b). Models of Critical Gaps and Follow-up Headways for turbo Roundabouts. In: E. Macioszek, R. Akçelik, G. Sierpiński (eds.) Roundabouts as Safe and Modern Solutions in Transport Networks and Systems. Lecture Notes in Networks and Systems 52. Springer International Publishing Switzerland 2019, p. 124-134.

Macioszek, E. (2019c). Changes in Values of Traffic Volume Case Study Based on General Traffic Measurements in Opolskie Voivodeship (Poland). In: E. Macioszek, G. Sierpiński (eds.) Directions of Development of Transport Networks and Traffic Engineering. Lecture Notes in Networks and Systems 51. Springer International Publishing Switzerland 2019, p. 66-76.
Macioszek, E. (2019d). Models of Critical Gaps and Follow-up Headways for turbo Roundabouts. In: E. Macioszek, R. Akçelik, G. Sierpiński (eds.) Roundabouts as Safe and Modern Solutions in Transport Networks and Systems. Lecture Notes in Networks and Systems 52. Springer International Publishing Switzerland 2019, p. 124-134.

Mackie, H.W., Charlton, S.G., Baas, P.H., Villasenor, P.C. (2013). Road user behaviour changes following a self-explaining roads intervention. Accident Analysis \& Prevention, 50, 742-750.

Małecki, K. (2017). The Use of Heterogeneous Cellular Automata to Study the Capacity of the Roundabout. In: L. Rutkowski, M. Korytkowski, R. Scherer, R., Tadeusiewicz, L. Zadeh, J.Zurada (eds.) Artificial Intelligence and Soft Computing. ICAISC 2017. Lecture Notes in Computer Science 10246. Springer, Cham, p. 308-317.

Małecki, K. (2018). The Roundabout Micro-simulator Based on the Cellular Automaton Model. In: G. Sierpiński (eds.) Advanced Solutions of Transport Systems for Growing Mobility. TSTP 2017. Advances in Intelligent Systems and Computing 631. Springer, Cham, p. 40-49.

Małecki, K., Wątróbski, J., Wolski, W. (2017). A Cellular Automaton Based System for Traffic Analyses on the Roundabout. In: N. Nguyen, G. Papadopoulos, P. Jędrzejowicz, B. Trawiński, G. Vossen (eds.) Computational Collective Intelligence. ICCCI 2017. Lecture Notes in Computer Science 10449. Springer, Cham, p. 56-65.

Mandavilli, S., McCartt, A.T., Retting, R.A. (2009). Crash patterns and potential engineering countermeasures at Maryland roundabouts. Traffic Injury Prevention, 10, issue 1, 44-50.

Moller, M., Hels, T. (2008). Cyclist's perception of risk in roundabouts. Accident Analysis \& Prevention, 40, issue 3, 1055-1062.

Police Headquarters (2016). Road Accidents in Poland in 2016, https://statystyka.policja.pl/st/ruch-drogowy/76562,Wypadkidrogowe-raporty-roczne.html.

Retting, R.A., Persuad, B.N., Garder, P.E., Lord, D. (2001). Crash and injury reduction following installation of roundabouts in the United States. American Journal of Public Health, 91, issue 4, 628-631.

Saccomanno, F.F., Cunto, F., Guido, G. (2008). Comparing safety at signalized intersections and roundabouts using simulated rear-end conflicts. Transportation Research Record: Journal of the Transportation Research Board, vol. 2078, issue 1, p. 90-95.

Sharma, A., Zheng, Z., Bhaskar, A., Hague, M.M. (2019). Modelling car-following behaviour of connected vehicles with a focus on driver compliance. Transportation Research Part B: Methodological, vol. 126, pp. 256-279.

Sładkowski, A., Cieśla, M. (2018). Analysis and development perspective scenarios of transport corridors supporting eurasian trade. In: Sładkowski, A. (ed.) Transport Systems and Delivery of Cargo on East-West Routes. Studies in Systems, Decision and Control 155, Springer, Cham, p. 71-119.

Statistical Yearbook of Masovian Voivodeship (2017). http:// warszawa.stat.gov.pl/publikacje-i-foldery/roczniki-statystyczne/rocznik-statystyczny-wojewodztwa-mazowieckiego-2016,4,16.html (accessed: 2017-10-17). 
Streiner, D. (2003). Starting at the beginning: An introduction to coefficient alpha and internal consistency. J. Personal. Assess. 80, p. 99-103.

Szczucka-Lasota, B. (2017). City logistics: influence of oversized road transport on urban development. Scientific Journal of Silesian University of Technology. Series Transport 97, p. 157-165.

Sullman, M.J.M., Meadows, M., Pajo, K.B. (2002). Aberrant driving behaviours amongs New Zealand truck drivers. Transportation Research Part F: Traffic Psychology and Behaviour, vol. 5, issue 3, pp. 2170232.

Szczuraszek, T., Macioszek, E. (2013). Proportion of Vehicles Moving Freely Depending on Traffic Volume and Proportion of Trucks and Buses. The Baltic Journal of Road and Bridge Engineering, vol. 8, no 2, pp. 133-141.

Szczuraszek, T., Macioszek, E. (2010). Analiza rozkładów odstępów czasu pomiędzy pojazdami na obwiedni małych rond (Analysis of time intervals distribution between vehicles on the roadway around central island of small roundabouts). Drogi i Mosty. Instytut Badawczy Dróg i Mostów, Rocznik 9, 3/2010, s. 87-99. Warszawa 2010.

Tavakol, M.; Dennick, R. (2011) Making sense of Cronbach's alpha. Int. J. Med Educ. 2, p. 53-55.

Wahlberg, A. (2009). Driver Behaviour and Accident Research Methodology. Inresolved Problems. London, CRC Press.

Yurdugul, H. (2008). Minimum sample size for Cronbach's coefficient alpha: A Monte-Carlo study. Hacet. Univ. J. Educ. 35, p. 397-405. 